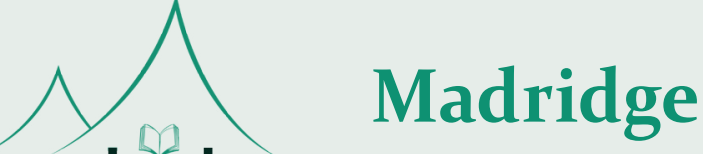 \\ madridge Journal of Dermatology \& Research \\ interconnectin
}

Case Report

Open Access

\section{Cutaneous Metastasis from Squamous Cell Carcinoma Lung}

\author{
Jayabal Pandiaraja ${ }^{1 \star}$ and A. Shalini ${ }^{2}$ \\ ${ }^{1}$ Consultant, Care hospital, Villivakkam, Chennai, India \\ ${ }^{2}$ Assistant professor, ACS medical college, Velappanchavadi, Chennai, India
}

\section{Article Info}

\author{
*Corresponding author: \\ Jayabal Pandiaraja \\ Consultant \\ Care hospital \\ Chennai \\ Pin: 600049 \\ India \\ E-mail:dr.pandiaraja@gmail.com
}

Received: November 29, 2017

Accepted: December 4, 2017

Published: December 9, 2017

Citation: Pandiaraja J, Shalini A. Cutaneous Metastasis from Squamous Cell Carcinoma Lung. Madridge J Dermatol Res. 2017; 2(1): 23-25.

doi: 10.18689/mjdr-1000106

Copyright: ๑ 2017 The Author(s). This work is licensed under a Creative Commons Attribution 4.0 International License, which permits unrestricted use, distribution, and reproduction in any medium, provided the original work is properly cited.

Published by Madridge Publishers

\begin{abstract}
Cutaneous metastasis may be the first sign of internal malignancy. In lung carcinoma skin is $13^{\text {th }}$ common site of metastasis. Other sites includes hilar node, liver, adrenal gland, bones, brain are the most frequent site of metastasis. Cutaneous metastasis occurs as an initial presentation in $0.8 \%$ of patient with internal malignancy. Here we report a case of squamous cell carcinoma of right lung with left side back metastasis. This case was reported due to uncommon site and uncommon side of lung metastasis.
\end{abstract}

Keywords: Squamous Cell Carcinoma; Cutaneous Growth; Metastasis; Lung.

\section{Introduction}

Cutaneous nodule occurs following internal malignancy is very rare. Cutaneous metastasis is defined as group of malignant cells in the skin due to internal malignancy. Most of the time cutaneous nodule was detected after initial diagnosis of primary lesion. But in sometime it may be detected before or same time of detection of primary malignancy [1]. Incidence of Cutaneous metastasis is varies from $0.7 \%$ to $9 \%$. In male lung (24\%) is the most common site for cutaneous metastasis followed by colon (19\%), melanoma (13\%) and oral cavity (12\%). In women breast (69\%) is the most common site followed by colon (9\%), melanoma (5\%), ovary (4\%) and lung (4\%) [2]. But recent trial showed higher incidence of cutaneous metastasis following melanoma (32.3\%) in male.

\section{Case Report}

A 35-year-old male who is a chronic smoker for 20 years, presented with complaint of ulcerated growth over the left side of back for 1 month duration. There was history of pain over the growth for 1 month duration. Patient said there is a history of loss of appetite and loss of weight. Patient was initially treated for squamous cell carcinoma right cheek with curative radiotherapy. Local examination of back revealed an ulcerated growth of $4 \times 3 \mathrm{~cm}$ present on the left side of back. The growth covered with necrotic base with fresh bleeding and foul smelling discharge. The growth was hard in consistency. There was evidence of left axillary lymphadenopathy [Figure 1]. 


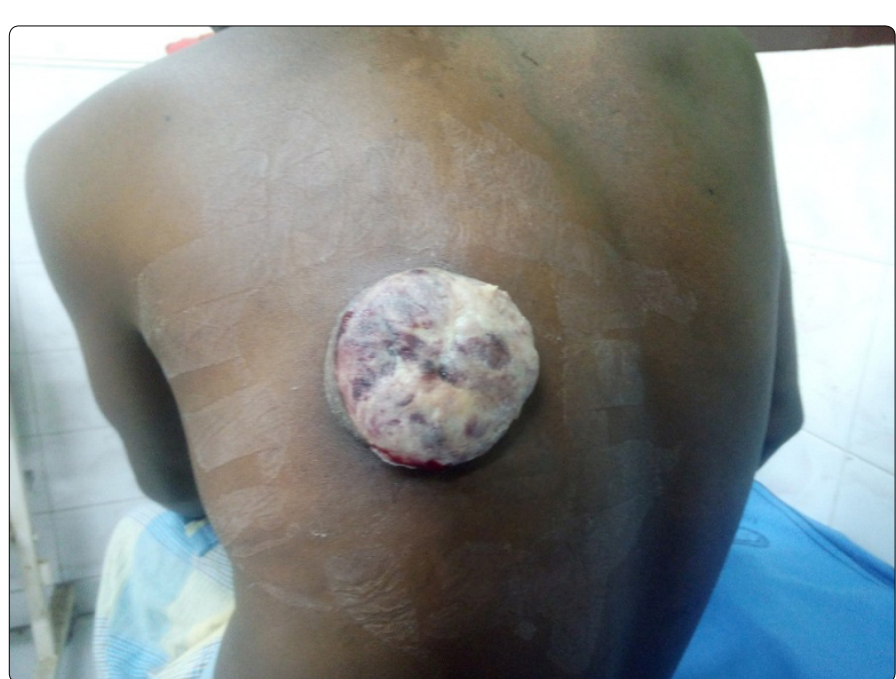

Figure 1. An ulcerated growth of $4 \times 3 \mathrm{~cm}$ present on the left side of back

Routine blood examination like complete blood count, renal function test and liver function test were normal. Edge biopsy of left back growth showed well differentiated squamous cell carcinoma [Figure 2].

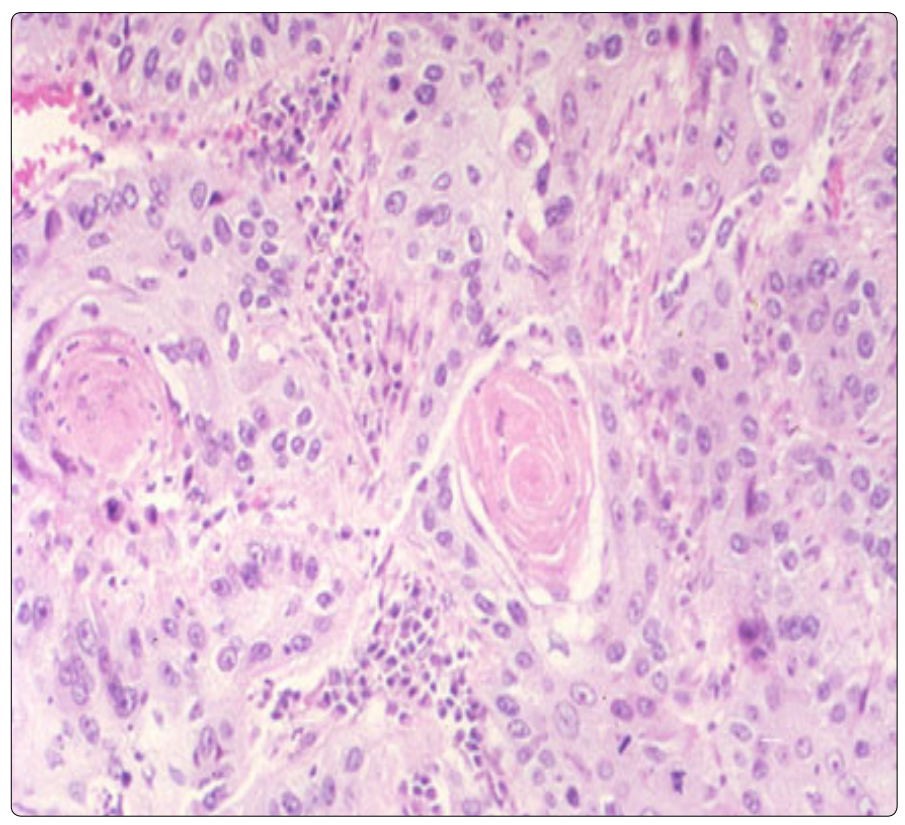

Figure 2. Edge biopsy of left back growth showed well differentiated squamous cell carcinoma

Whether squamous cell carcinoma left back is primary or metastatic we are not sure. So we took biopsy form oral cavity. The biopsy from the oral cavity showed reactive inflammatory tissue and no evidence of residual malignancy. Computed tomography chest showed well defined heterogenously enhancing lesion of $6.2 \times 3.5 \mathrm{~cm}$ involving the skin, subcutaneous and muscular plane of the left side of back in the infrascapular region along with well defined lesion with irregular spiculated margin of $7.4 \times 4.9 \times 4.5 \mathrm{~cm}$ in the apical segment of right upper lobe showing heterogenous enhancement with few areas of non enhancing necrotic component on contrast study [Figure $3 a \& b$ ].

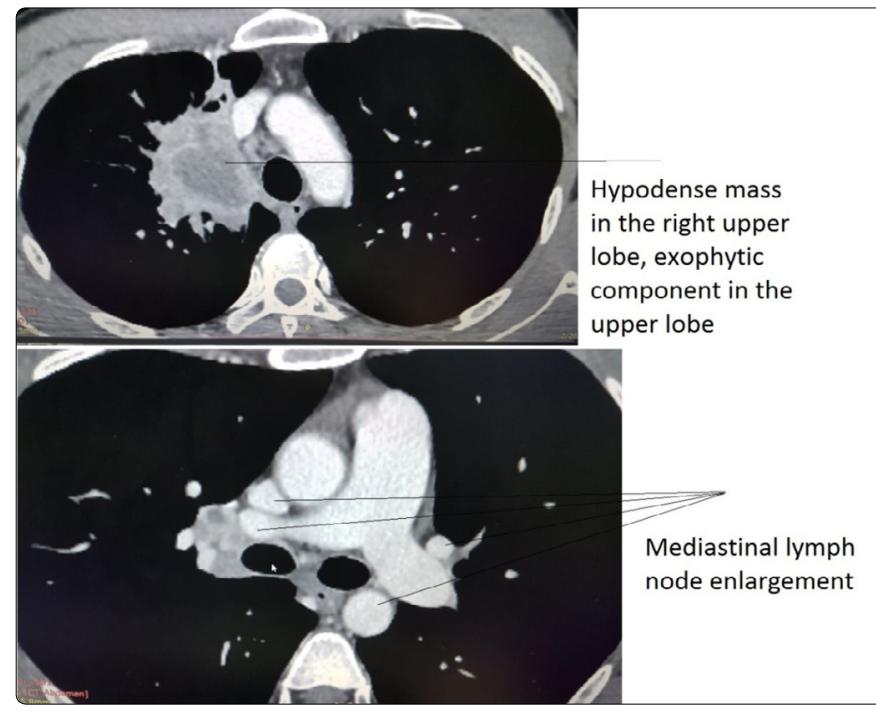

Figure 3a \& b. CT chest showed well defined heterogenously enhancing lesion of $6.2 \times 3.5 \mathrm{~cm}$ involving the skin, subcutaneous and muscular plane of the left side of back in the infrascapular region along with well defined lesion with irregular spiculated margin of $7.4 \times 4.9 \times 4.5 \mathrm{~cm}$ in the apical segment of right upper lobe showing heterogenous enhancement with few areas of non enhancing necrotic component.

Broncoscopy showed upper lobe right bronchus completely occluded with endobronchial growth which bleeds on touch [Figure 4].

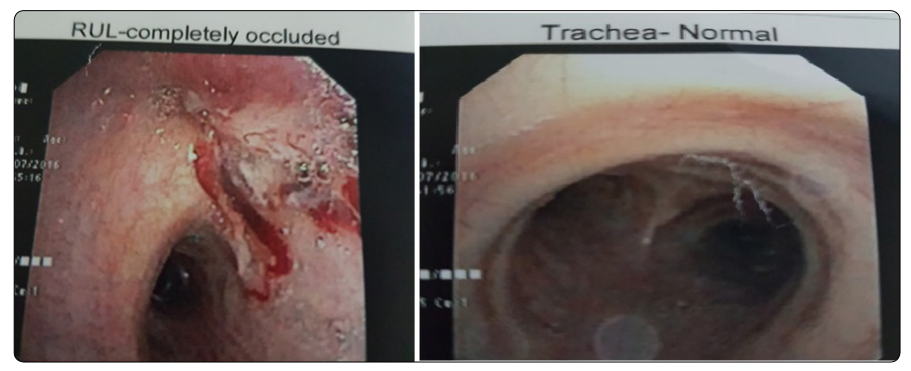

Figure 4. Broncoscopy showed upper lobe right bronchus completely occluded with endobronchial growth

Biopsy from bronchial growth showed well differentiated squamous cell carcinoma [Figure 5].

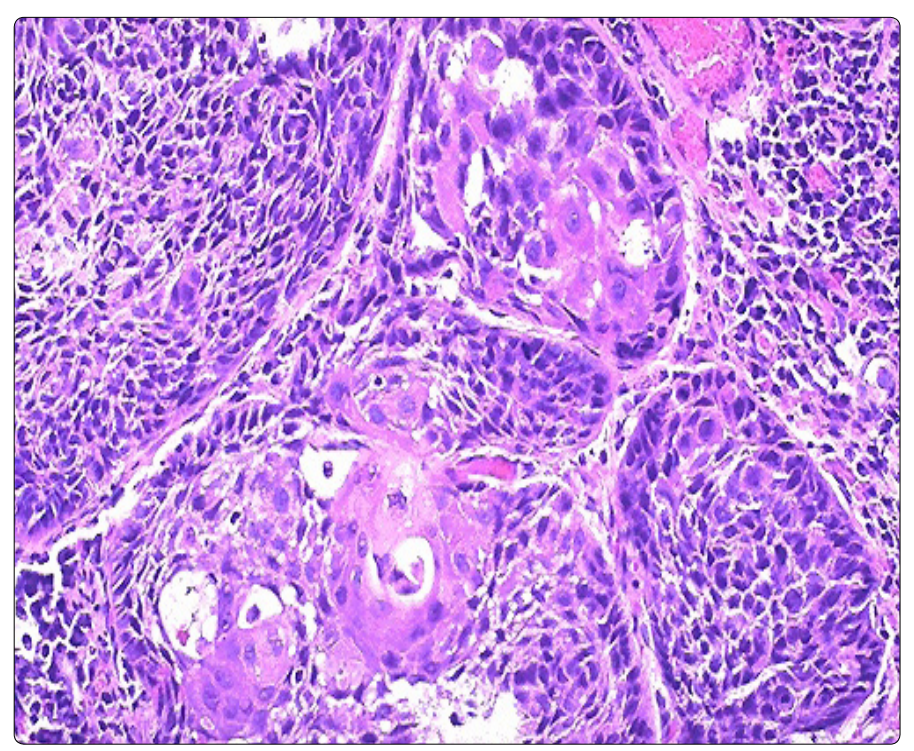

Figure 5. Biopsy from bronchial growth showed well differentiated squamous cell carcinoma 
Patient was offered palliative chemotherapy. Patient died after 4 months following chemotherapy.

\section{Discussion}

Cutaneous metastasis of internal malignancy may be nodular or ulcerated, mobile or fixed, single or multiple and painful or painless lesion [3]. There is lot of controversy in which type of lung carcinoma has high incidence of metastasis. Kanazawa \&Hidaka et al showed high incidence of cutaneous metastasis in large cell carcinoma than squamous or small cell carcinoma. Dreizen et al showed adenocarcinoma has highest tendency for cutaneous metastasis, whereas Brown stein \& Helwing et al reported adenocarcinoma and squamous cell carcinoma has equal incidence of cutaneous metastasis.

The incidence of cutaneous metastasis in lung cancer varies from $1 \%$ to $12 \%$ [4]. Most of the cases nodule occurs in the same side of lesion. But in our case it is different. It occurred on the opposite side of the primary lesion. Nodule commonly seen in the chest, abdomen, scalp, head and neck, extremities and rarely over back [5]. In our case it occurred over the back. In most of the cases cutaneous nodule is indistinguishable from the primary cutaneous malignancy or metastatic nodule.

Adenocarcinoma lung has high incidence of cutaneous metastasis than squamous cell carcinoma [6]. Metastatic deposit from squamous cell carcinoma mostly moderately differentiated or poorly differentiated. Cutaneous metastasis occur either lymphatic or hematogenous route. Carcinoma lung mostly spread via hematogenous route [7]. This is the reason for occurrence of cutaneous nodule in lung carcinoma anywhere in the body. Most of the cases managed with combined chemo radiation. But the prognosis is very poor for malignancy with cutaneous deposit. The median survival following cutaneous metastasis varies from 3 months- 6 months [8].

\section{Conclusion}

Cutaneous metastasis should be suspected in patient who is a chronic smoker or previous history of squamous cell carcinoma. It may be the only manifestations of internal malignancy, when internal malignancy is silent. The prognosis of internal malignancy with cutaneous metastasis is always poor. Even with best available combination chemotherapy or radiotherapy the chance of survival is poor.

\section{References}

1. Abdeen $Y$, Amireh $S$, Patel A, Al-Halawani M'd, Shaaban $H$, Miller R. Cutaneous Metastasis as a First Presentation for Lung Adenocarcinoma. North Am J Med Sci. 2016; 8(5): 222-225. doi: 10.4103/1947-2714.183010

2. Pathak $S$, Joshi $S R$, Jaison J, Kendre D. Cutaneous metastasis from carcinoma of lung. Indian Dermatol Online J. 2013; 4(3): 185-187. doi: 10.4103/2229-5178.115512

3. Pajaziti L, Hapçiu SR, Dobruna S, Hoxha N, Kurshumliu F, Pajaziti A. Skin metastases from lung cancer: a case report. BMC Res Notes. 2015; 8: 139. doi: 10.1186/s13104-015-1105-0

4. Thurston $D$, Hossain $T$, Waraich N, Shukla A. Non-small cell lung cancer with distal cutaneous metastases in a patient with a previously treated colorectal carcinoma. Ann R Coll Surg Engl. 2016; 98(3): 47-48. doi: 10.1308/rcsann.2016.0088

5. Elfatoiki FZ, Hali F. Cutaneous metastasis reveling lung cancer. Pan Afr Med J. 2015; 20:19. doi: 10.11604/pamj.2015.20.19.5883

6. Lu S, Yang J, Sun Y, Xu Z. Multiple cutaneous and intestinal metastases in lung cancer: A case report. Oncol Lett. 2015; 9(4): 1541-1544. doi: 10.3892/ ol.2015.2893

7. Bhattarai B, Schmidt MF, Ghosh M, et al. Lung cancer with skin and breast metastasis: a case report and literature review. Case Rep Pulmonol. 2015; 136970. doi: $10.1155 / 2015 / 136970$

8. Scott GD, Kwong BY, Novoa RA. Epidermotropic metastasis of primary lung adenocarcinoma. J Cutan Pathol. 2016; 43(9): 798-801. doi: 10.1111/ cup. 12741 